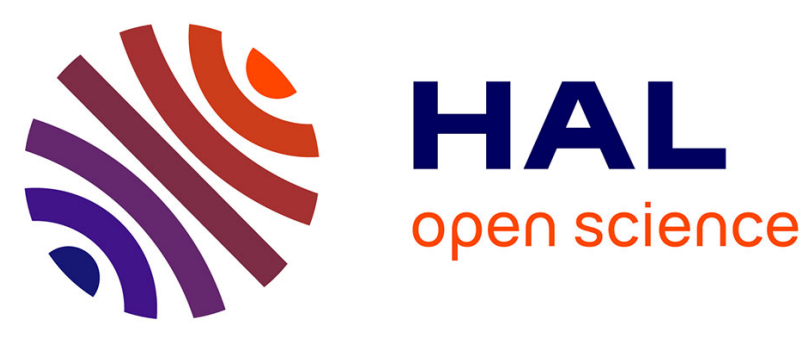

\title{
Behavior of CVD diamond-based TL dosimeters in radiotherapy environments using photon and electron beams from treatment accelerators
}

M. Benabdesselam, A. Petitfils, Frédéric Wrobel, F. Mady, S. Marcié, Etienne Gheeraert

\section{To cite this version:}

M. Benabdesselam, A. Petitfils, Frédéric Wrobel, F. Mady, S. Marcié, et al.. Behavior of CVD diamond-based TL dosimeters in radiotherapy environments using photon and electron beams from treatment accelerators. 21st Conference on Diamond, Diamond like Materials, Carbon Nanotubes and Nitrides, Sep 2010, Budapest, Hungary. hal-01307873

\section{HAL Id: hal-01307873 https://hal.science/hal-01307873}

Submitted on 28 Apr 2016

HAL is a multi-disciplinary open access archive for the deposit and dissemination of scientific research documents, whether they are published or not. The documents may come from teaching and research institutions in France or abroad, or from public or private research centers.
L'archive ouverte pluridisciplinaire HAL, est destinée au dépôt et à la diffusion de documents scientifiques de niveau recherche, publiés ou non, émanant des établissements d'enseignement et de recherche français ou étrangers, des laboratoires publics ou privés. 


\title{
Behavior of CVD diamond-based TL dosimeters in radiotherapy environments using photon and electron beams from treatment accelerators.
}

\author{
M. Benabdesselam ${ }^{1}$, A. Petitfils ${ }^{1}$, F. Wrobel ${ }^{2}$, F. Mady ${ }^{1}$, S. Marcié ${ }^{3}$, E. Gheeraert ${ }^{4}$ \\ ${ }^{1}$ Université de Nice-Sophia Antipolis, Laboratoire de Physique de la Matière Condensée, \\ CNRS UMR 6622, Parc Valrose, 06108 Nice CEDEX 2, France. \\ ${ }^{2}$ Université de Montpellier II, Institut d'Electronique du Sud (IES), place Eugène Bataillon, \\ 34095 Montpellier cedex 5, France. \\ ${ }^{3}$ Centre Antoine Lacassagne, 33 Avenue Valombrose, 06189 Nice cedex 2, France. \\ ${ }^{4}$ Institut Néel, CNRS and Université Joseph Fourier, 25 avenue des Martyrs, BP166, 38042 \\ Grenoble Cedex 9, France.
}

E-mail: ben@unice.fr (M. Benabdesselam)

\begin{abstract}
Chemical Vapor Deposited (CVD) diamond has great advantages for use as thermoluminescent dosimeters in radiotherapy environment because of the reproducible high quality and controlled doping. This study compares CVD diamond Thermally Stimulated Luminescence response to that of a classical ionization chamber. Clinicallyrelevant features like the depth-dose distributions as well as the absorbed dose profile are investigated for a $6 \mathrm{MV}$ photon beam and a $6 \mathrm{MeV}$ electron beam. Moreover electron beam cartography and one beam Intensity-Modulated Radiation Therapy (IMRT) treatment planning have been controlled by means of CVD diamonds. Reproducibility and repeatability of TL measurements are satisfying and a good TL sensitivity to both electron and photon beams is clearly shown. Comparing the TL responses presented here to the ionization chamber underline the very promising behavior of CVD diamonds, particularly in high dose gradient areas.
\end{abstract}

Keywords: CVD diamond, thermoluminescence, dosimetry, photon and electron beams. 


\section{Introduction}

The outstanding advantages of diamond for TL dosimetry in medical environment are well known: human tissue equivalence, chemical inertness, mechanical robustness, re-use and sterilization by simple heating. Diamond should then be an excellent candidate for in vivo radiation dosimetry.

The use of natural diamonds for TL dosimetry in medical environment was first presented by Carter since the end of seventies (1977). Nevertheless the extensive use of natural stoness has not been viable due to the lack of reproducibility, scarcity and the prohibitive cost. With the advent of High Pressure High Temperature (HPHT) and CVD synthesis processes of this diamond, a large body of work has been carried out on use of synthetic diamonds for ionizing radiation dosimetry by TL presented by Keddy and Nam (1993), Buttar et al (1997), Bogani et al (1997) and Marczewska et al (2002). During this last decade, some studies of Mazzocchi et al (2002) and Borchi et al (1998) underlined convenient TL properties of CVD diamond for radiotherapy and highlighted many advantages compared to the commercially available thermoluminescent dosimeters (TLD) used extensively in radiotherapy centers, as reported by Benabdesselam et al (2000).

The aim of this paper is to confirm the applicability of CVD diamond as a TLD in radiotherapy environments. For this purpose, the diamond samples were tested under electron and photon beams delivered by linear accelerators used in radiotherapy treatments and the results are compared with those of ionization chamber detector.

\section{Materials and experimental details}

Measurements were carried out on a set of 21 unintentionally doped free-standing polycrystalline diamonds films synthesized at the Naval Research Laboratory (NRL) by microwave plasma-assisted CVD. Growth was realized on a tungsten substrate heated at 1023 $\mathrm{K}$ with a microwave power of $4.5 \mathrm{~kW}$ and a gas pressure of $15.4 \mathrm{kPa}$. Flow rates of hydrogen 
and methane were 156 and $6.3 \mathrm{sccm}$ respectively. Dimensions of the studied films are squares of $(5 \cdot 5) \mathrm{mm}^{2}$ and $260 \mu \mathrm{m}$ thick.

Prior to TL measurements, CVD samples were irradiated at room temperature (RT) by either an electron or a photon beam. Electron beam of $6 \mathrm{MeV}$ was delivered by a linear electron accelerator MXE (Siemens) while the photon beam was provided by another linear accelerator PRIMUS (Siemens) working at an accelerating nominal voltage of $6 \mathrm{MV}$. For each type of irradiations, the delivered Monitor Unit (MU) rate was $300 \mathrm{MU} / \mathrm{min}$. This unit is a measure of machine output of linear accelerators in radiation therapy. In this experimental setup $1 \mathrm{MU}$ corresponds to about $0,86 \mathrm{cGy}$ for $6 \mathrm{MeV}$ electrons at maximum. In the case of 6 MV photons, $1 \mathrm{MU}$ corresponds to $0,813 \mathrm{cGy}$ for the reference conditions $\left(10 \mathrm{x} 10 \mathrm{~cm}^{2}\right.$ field size and $10 \mathrm{~cm}$ depth in water).

For all measures, the SSD, referring to the source-to-surface distance was $100 \mathrm{~cm}$. The used field sizes were $10 \times 10$ or $20 \times 20 \mathrm{~cm}^{2}$ for equivalent delivered doses of 200 and $400 \mathrm{MU}$ respectively.

For comparison to the TL results with the CVD diamond samples, a $0.13 \mathrm{~cm}^{3}$ sensitive volume ionization chamber with a cavity length of $5.8 \mathrm{~mm}$ (model Scanditronix Wellhöfer IC 15 waterproof) was used in conjunction with a WP 5007 Wellhöfer electrometer.

TL features like reproducibility, repeatability, absorbed dose profile and $6 \mathrm{MeV}$ electron beam cartography were studied with a PMMA (PolyMethyl MethAcrylate) phantom consisting of around 20 slabs of 1 and $0,4 \mathrm{~cm}$ thick whereas depth-dose distributions were measured in a $(56 \times 60 \times 44) \mathrm{cm}^{3}$ water phantom. Reproducibility and repeatability values were obtained after 5 irradiation-TL readout cycles. All measurements with the ionization chamber were done in the water phantom.

TL readout was performed by means of a S13 response photomultiplier covering the spectral range $300-600 \mathrm{~nm}$. To isolate the dosimetric TL peak and to suppress any unstable 
low-temperature components, a cycle of preheating up to $483 \mathrm{~K}$ followed by cooling down to RT is performed. The sample is then heated again from RT to $673 \mathrm{~K}$ with a linear heating rate of $1 \mathrm{~K} / \mathrm{s}$ and the TL signal recorded. Previous works of Petitfils et al (2007) and Benabdesselam et al (2008) on these diamond films underlined the consequences on TL of using different heating rates and the calibration of the films.

\section{Results and discussion}

\subsection{TL response of CVD diamonds}

\subsubsection{Sample characterization and TL features.}

A typical TL glow curve has been already measured for our samples shows a shoulder at around $350 \mathrm{~K}$ and a main component peaking at $550 \mathrm{~K}$ (Figure 1). This latter is particularly well suited for TL dosimetry. Indeed, the temperature of $550 \mathrm{~K}$ is high enough to not empty traps linked to the dosimetric peak (during storage at RT) and at the same time, sufficiently low as not to be affected by black-body radiation appearing with increasing temperature. Henceforth, this peak will be referred as the "dosimetric peak". The trap parameters relative to this peak have been determined: the activation energy and frequency escape factor are $\mathrm{E}=$ $1.22 \mathrm{eV}$ and $\mathrm{s}=3 \cdot 10^{9} \mathrm{~s}^{-1}$ respectively. The spectral distribution of this dosimetric peak is a single and broad band peaking at $2.54 \mathrm{eV}$ with a FWHM of $0.58 \mathrm{eV}$ (Benabdesselam et al 2003). This band is the so-called A-band luminescence, well known in CVD diamond and which is due to the grain-boundary $\mathrm{sp}^{2}$ impurities and dislocations in polycrystalline diamond as shown by Takeuchi et al (2001).

\subsubsection{Simultaneous use of 21 CVD diamond films.}

First, reproducibility and repeatability of the TL response of 21 diamond films with both 6 $\mathrm{MeV}$ electron and $6 \mathrm{MV}$ photon beam irradiations have been studied. Reproducibility corresponds to the TL response dispersion between samples while the repeatability is the deviation of TL response for an individual sample. 
For each sample, the estimated repeatability ranges from 0.4 to $3 \%$ for irradiation in an electron beam and from 0.5 to $4 \%$ in a photon one. For an application in medical environment, the IAEA protocol 398 recommends the use of dosimeters with TL response repeatability less than $0.5 \%$. It is important to note that although the CVD diamond films were not specially provided for TL dosimetry, some among the studied films seem to meet the requirements for use in medical applications (13 films against $6 \mathrm{MeV}$ electrons and 10 against $6 \mathrm{MV}$ photons). The reproducibility of measurements on each sample is less than $5 \%$. These values which might be considered as relatively high are due to inhomogeneity across the grown diamond wafer: some variations in the plasma environment during CVD synthesis and mass discrepancies in the films are observed. Thus, before any use, a sample calibration was undertaken and dose TL response curves were measured for each of the 21 samples in the range [2 - $450 \mathrm{MU}]$ for both electron and photon irradiations. After each mode of irradiation (6 $\mathrm{MeV}$ electrons and $6 \mathrm{MV}$ photons), the TL peak area is then plotted as a function of the equivalent number of MU delivered by the accelerator. A home-made application program regrouping all of the calibration curves is then created for each mode of irradiation. This application program allows the absorbed dose in a CVD diamond sample to be derived from the TL dosimetric peak area. This calibration process would allow simultaneous use of the 21 CVD diamond films in real radiotherapy experiments.

\subsection{CVD diamond TL response under clinical irradiation conditions}

Clinically-relevant features that are dose profiles and depth-dose distributions are an important part of beam quality control of treatment accelerators in radiotherapy. Measurements of these two important features were carried out by comparing TL results from CVD diamond films to those obtained with a commercial ionization chamber. 


\subsubsection{Dose profiles.}

For a $10 \times 10 \mathrm{~cm}^{2}$ size beam of $6 \mathrm{MV}$ photons, the dose profiles shown in Figure 2 reveal a quiet good agreement between CVD diamond TL response and ionization chamber readings. This result underlines particularly the accuracy of diamonds TL response in the penumbra area of the beam field where a very high dose gradient occurs. Similar results are obtained for a larger $(20 \times 20) \mathrm{cm}^{2}$ size of the same beam.

Dose profiles resulting from electron beams have also been measured but are not reported here. These results are quite similar to those presented in this work.

\subsubsection{Depth-dose distribution.}

The depth-dose distributions have been measured in water for both $6 \mathrm{MV}$ photons and $6 \mathrm{MeV}$ electrons. For each mode of irradiation, CVD diamond TL responses match well the readings of the ionization chamber. One can see in Figure 3 that even for incident electrons of higher energy $(12 \mathrm{MeV})$, good agreement between both types of measurements is observed particularly between 3,6 and 5,8 cm where the dose gradient is the highest.

\subsubsection{Cartography of the absorbed dose.}

In addition to dose profile and depth dose distribution, we undertook to realize cartographyThe cartography (usually referred as isodose distribution) of $6 \mathrm{MeV}$ electrons beam by means of 21 CVD diamond films. Measurements have been achieved in a PMMA phantom (SSD of $100 \mathrm{~cm}$ and $(10 \times 10) \mathrm{cm}^{2}$ field size) and in order to get a sufficient number (200) of measurements points, the irradiations were performed over many successive days (during 10 days at 20 measurements per day). For each set of measurements, CVD films were judiciously placed at different places so as to cover the entire field of radiation. Despite some fluctuations due to not high enough number of measurements points (200) and to the interpolation method, the two-dimensional (2D) beam cartography shown in Figure 4 is just 
an indicative representation of the beam cartography since, in theory, the electron beam isodoses would form regular squares in this 2D-representation.

\section{Summary}

Previous literature discussed CVD diamond materials as having many advantages for future TL dosimeters. From the results presented in this work, one can see that CVD diamond films might be capable of impacting all clinical dosimetry fields even for electron beam dosimetry where the gradient of the energy transfer in tissue is severe.

The reproducibility and repeatability of the TL measurements presented here are quite satisfactory but efforts must be improved in the uniformity of synthesis-process and efforts must be provided by optimizing the deposition rate and ensuring a better control of the plasma environment. These efforts will no doubt lead to the achievement of CVD diamond TLDs that meet the standard recommendations of use in TL dosimetry and to the reduction of the calibration steps even if CVD diamond, unlike some commercial dosimeters, which do not require a prior any particular treatment sometimes is tedious.

Moreover, for specific applications of clinical dosimetry where a high spatial resolution is needed, smaller volumes $\left(<1 \mathrm{~mm}^{3}\right)$ diamond films and judicious intentional doping during the growth would allow more accurate responses.

Despite the relatively low number of measurements points shown in the $2 \mathrm{D}$ cartography, one can conclude that the use of a higher number of films with a uniform and smaller volume to irradiate in one day will improve the electron beam cartography.

Acknowledgements

The authors want to thank gratefully Dr. J. E. Butler from Naval Research Laboratory for supply of the CVD diamond films. 


\section{References}

Carter A 1977 Indus. Diam. Rev. 239

Keddy R J and Nam, T L 1993 Radiat. Phys. Chem. 41, 767

Buttar C M, Conway J, Meyfarth R, Scarsbrook G, Sellin P J, A. Whitehead A 1997 Nucl. Instrum. Meth. A 392, 281

Bogani F, Borchi E, Bruzzi M, Leroy C, Sciortino S 1997 Nucl. Instrum. Meth. A 388, 427

Marczewska B, Bilsky P, Nesladek M, Olko P, Rebisz M, Waligorski M P R 2002, phys. stat. sol. (a) 193, 470

Mazzocchi S, Bruzzi M, Bucciolini M, Cuttone G, Pini S; Sabini M G, Sciortino S 2002 Nucl. Instrum. Meth. A 476, 713

Borchi E, Bruzzi M, Leroy C, Sciortino S 1998 J. Phys.D: Appl. Phys. 31, 609

Petitfils A, Wrobel F, Benabdesselam M, Iacconi P, Butler J E 2007 Diam. Relat. Mater. 16, 1062

Benabdesselam M, Petitfils A, Wrobel F, Butler J E, Mady F 2008 J. Appl. Phys 103, 114908

Benabdesselam M, Iacconi P, Butler J E, Nigoul J M 2003 Diam. Relat. Mater. 12, 1750

Takeuchi D, Watanabe H, Yamanaka S, Okushi, Sawada H, Ichinose H, Sekiguchi T, Kajimura K 2001 Phys. Rev. B 63, 245328

ICRU 1987 Technical reports series n² 277, IAEA, Vienna 


\section{FIGURES CAPTIONS}

Figure 1. A typical TL curve obtained after either electron or photon beam irradiations.

Figure 2. The measured dose profiles with ionization chamber and CVD diamond TL dosimeter resulting from a $6 \mathrm{MV}$ photon beam at $5 \mathrm{~cm}$ depth in water for a beam field size of $(10 \times 10) \mathrm{cm}^{2}$.

Figure 3. The depth-dose distribution measured with ionization chamber and CVD diamond dosimeters resulting from a $12 \mathrm{MeV}$ electron beam and a field size of $(10 \cdot 10) \mathrm{cm}^{2}$ within a water phantom.

Figure 4. 2-D cartography of $6 \mathrm{MeV}$ electron beam resulting from CVD diamond TL responses in a $(10 \cdot 10) \mathrm{cm}^{2}$ field size and SSD of $100 \mathrm{~cm}$.

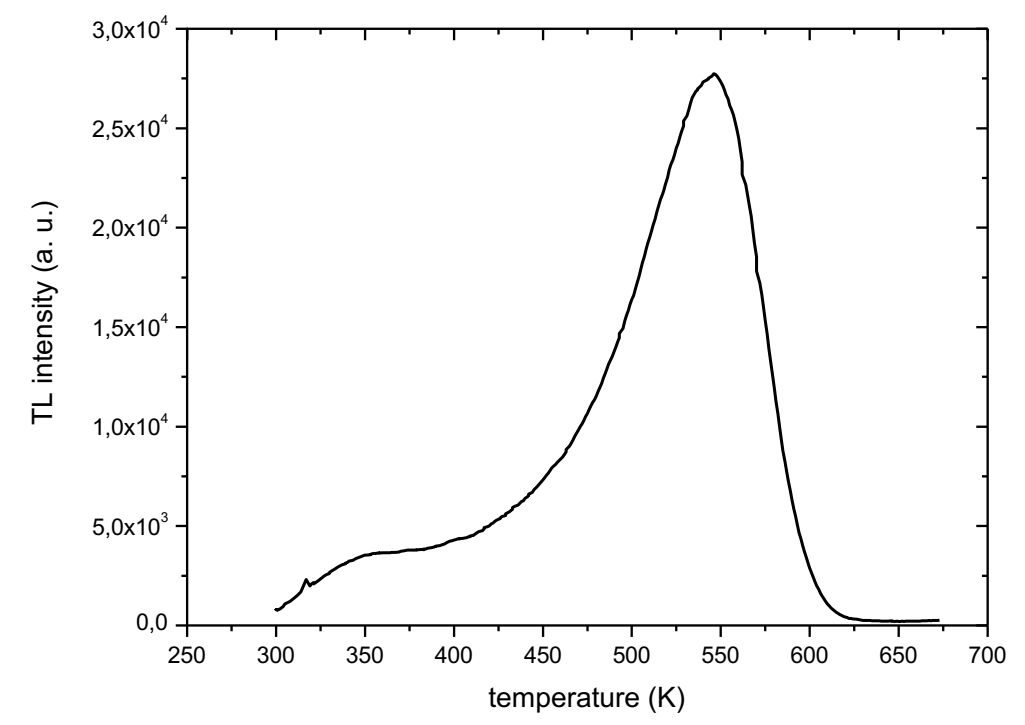

Figure 1 


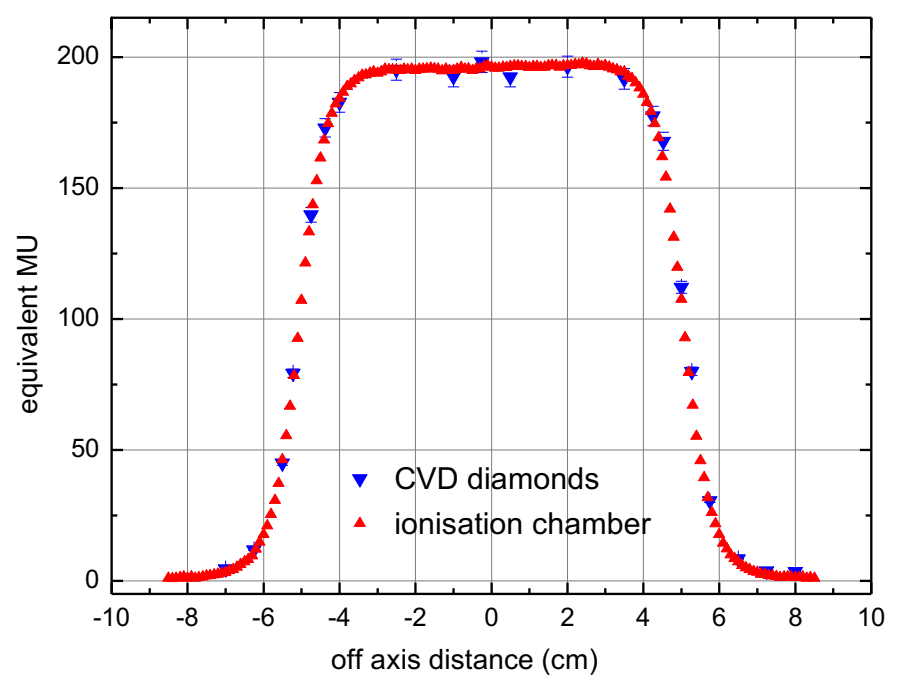

Figure 2

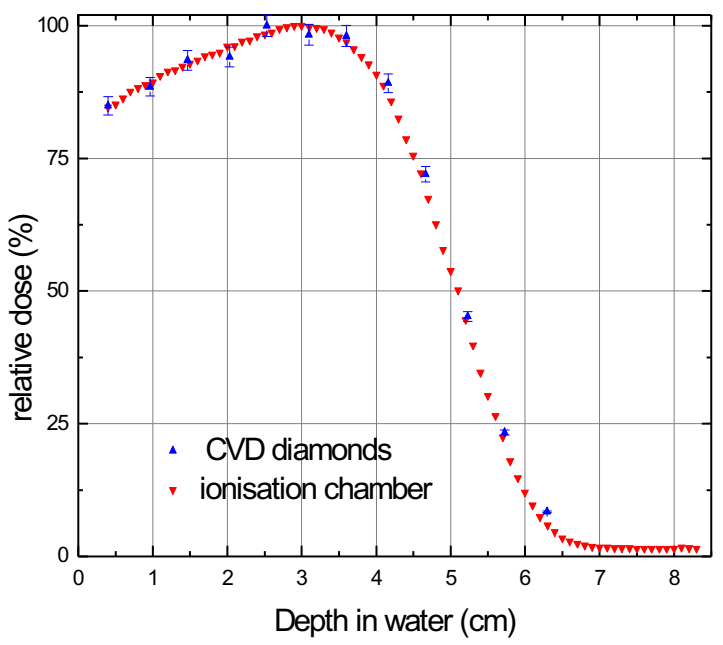

Figure 3 


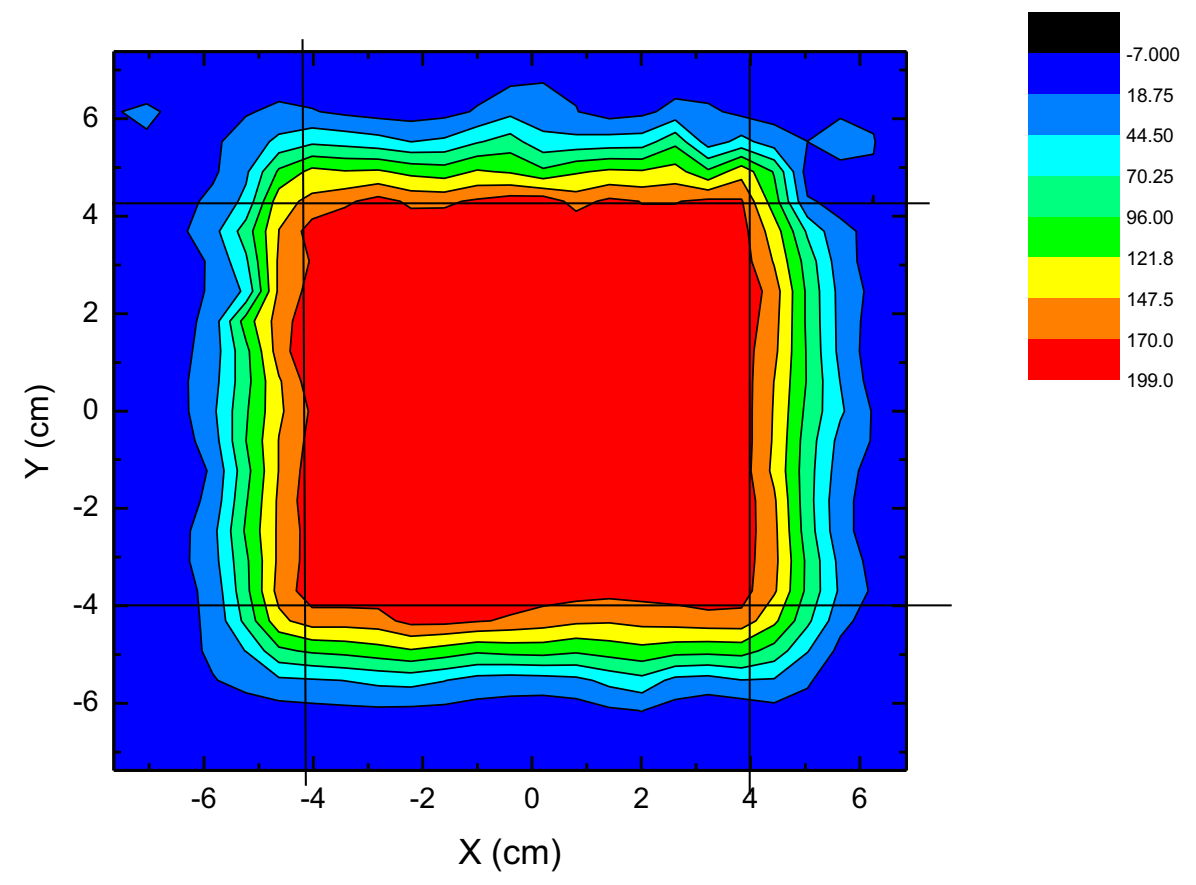

Figure 4 